\title{
Benign Blood Vessel Neoplasm
}

National Cancer Institute

\section{Source}

National Cancer Institute. Benign Blood Vessel Neoplasm. NCI Thesaurus. Code C8537.

A benign neoplasm arising from arteries or veins. 